\title{
Two-Tiered Inhibition of Axon Regeneration at the Dorsal Root Entry Zone
}

\author{
Matt S. Ramer, ${ }^{1,2}$ Ishwari Duraisingam, ${ }^{1}$ John V. Priestley, ${ }^{2}$ and Stephen B. McMahon ${ }^{1}$ \\ 'Sensory Function Group, Center for Neuroscience Research, Guy's King's and St. Thomas' School of Biomedical \\ Science, London SE1 1UL, United Kingdom, and 2Neuroscience Section, Division of Biomedical Science, St. \\ Bartholomew's and the Royal London School of Medicine and Dentistry, Queen Mary and Westfield College, London \\ E1 4NS, United Kingdom
}

\begin{abstract}
Glial-derived inhibitory molecules and a weak cell-body response prevent sensory axon regeneration into the spinal cord after dorsal root injury. Neurotrophic factors, particularly neurotrophin-3 (NT-3), may increase the regenerative capacity of sensory neurons after dorsal rhizotomy, allowing regeneration across the dorsal root entry zone (DREZ). Intrathecal NT-3, delivered at the time of injury, promoted an upregulation of the growth-associated protein GAP-43 primarily in large-diameter sensory profiles (which did not occur after rhizotomy alone), as well as regeneration of cholera toxin B-labeled sensory axons across the DREZ and deep into the dorsal horn. However, delaying treatment for 1 week compromised regeneration: although axons still penetrated the DREZ, growth within white matter was qualitatively and quantitatively restricted. This was not associated with an impaired cell-body response (GAP-43
\end{abstract}

The differential abilities of peripheral and central nervous tissue to support regeneration is exemplified at the dorsal root entry zone (DREZ), which marks the entry point of primary afferent axons into the spinal cord. Here, the environment changes abruptly from consisting of growth-permissive Schwann cells, to astrocytes, oligodendrocytes, and microglia, which may all inhibit regeneration (Fawcett and Asher, 1999). On contact with the DREZ, regenerating axons form club-like end bulbs or synapselike structures, (Ramon y Cajal, 1928; Carlstedt, 1985), but because of the prohibitive environment of the CNS and a paltry regenerative response of sensory neurons to rhizotomy, they never re-enter the adult cord.

One strategy to encourage regeneration is to enhance the growth response of the rhizotomized neurons. GAP-43 is induced in nearly all neurons during peripheral nerve regeneration (Verge et al., 1990b), but in few neurons after rhizotomy (Schreyer and Skene, 1993), unless the root is severed very close to the DRG (Chong et al., 1996). Dorsal root axonal growth occurs at about half the rate of peripheral axons (Wujek and Lasek, 1983; Oblinger and Lasek, 1984). An experimental "conditioning" lesion to a peripheral nerve before dorsal rhizotomy

\footnotetext{
Received Oct. 23, 2000; revised Jan. 12, 2001; accepted Jan. 19, 2001.

This work was supported by the European Union, the Wellcome Trust, and the Trustees of St. Thomas' Hospital. M.S.R. was supported by a fellowship from the Canadian Institutes of Health Research. Neurotrophin-3 was a gift of Genentech Inc.

Correspondence should be addressed to Dr. Matt Ramer, Sensory Function Group, Center for Neuroscience Research, Guy's King's and St. Thomas' School of Biomedical Science, Hodgkin Building, Guy's Campus, London Bridge, London SE1 1UL, UK. E-mail: matt.ramer@kcl.ac.uk.

Copyright (C) 2001 Society for Neuroscience 0270-6474/01/212651-10\$15.00/0
}

upregulation was equivalent for both immediate and delayed treatments), or with astrogliosis at the DREZ, which begins almost immediately after rhizotomy, but with the delayed appearance of mature ED1-expressing phagocytes in the dorsal white matter between 1 and 2 weeks after lesion, marking the beginning of myelin breakdown. After rhizotomy with immediate NT-3 treatment, regeneration continues beyond 2 weeks, but in the dorsal gray matter rather than in the degenerating dorsal columns. The ability of NT-3 to promote regeneration across the DREZ, but not after the beginning of degeneration after delayed treatment reveals a hierarchy of inhibitory influences: the astrogliotic, but not the degenerative barrier is surmountable by NT-3 treatment.

Key words: neurotrophin-3; regeneration; degeneration; astrocytes; oligodendrocytes; myelin; dorsal root ganglion doubles the rate of regeneration (Richardson and Verge, 1986) and improves the ability of axons to re-enter the spinal cord (Chong et al., 1999). Given that this approach is clinically unfeasible, an alternative is to increase the vigor of the regenerative machinery pharmacologically.

Neurotrophic factors are obvious candidates: first, targetderived neurotrophins nerve growth factor (NGF), brain-derived neurotrophic factor (BDNF), neurotrophin-3 (NT-3), and neurotrophin-4/5 (NT-4/5) are responsible for the appropriate development of different subclasses of sensory neurons (Lindsay, 1996). Second, neurotrophins can reverse many of the changes associated with axotomy in both the neonate and the adult, including cell loss (Eriksson et al., 1994), changes in neurochemistry (Verge et al., 1990a, 1992, 1995; Ohara et al., 1995; Sterne et al., 1998), physiology (Munson et al., 1997), and central connectivity (Bennett et al., 1996). And, not least of all, neurotrophic factors promote sensory neurite outgrowth in vitro (Gavazzi et al., 1999; Lentz et al., 1999), sometimes even in the presence of CNS-derived inhibitors (Cai et al., 1999).

We have previously found that NT-3 promotes the functional ingrowth of injured large-diameter afferent fibers into the spinal cord when treatment is begun at the time of rhizotomy (Ramer et al., 2000). One of the remaining questions is whether pre-existing injuries will be as amenable to this potential therapy. Here we show that delaying treatment by 1 week results in poorer regeneration of axons into the spinal cord. The underlying mechanism is not likely to involve an impaired rhizotomy-induced cell body response, or the immediate astrogliotic reaction to dorsal rhizotomy, but the delayed appearance of mature phagocytes marking 
the onset of myelin degeneration. Importantly, these results permit ranking of the regenerative barrier potency: NT-3 treatment allows axonal growth through reactive astrocytes, but only before the onset of Wallerian degeneration in the cord.

\section{MATERIALS AND METHODS}

Animal preparation. Animals underwent one of five procedures: rats in the "control" group $(n=8)$ received dorsal root injuries but remained untreated or received vehicle only ( $n=4,1$ week survival; $n=4$, 2 week survival); rats in the "immediate NT-3" group $(n=7)$ received intrathecal NT-3 treatment at the same time dorsal roots were injured (1 week, $n=5 ; 2$ weeks, $n=2$ ); and rats in the "delayed NT-3" group began intrathecal NT-3 treatment 1 week $(n=4)$ or 2 weeks $(n=5)$ after rhizotomy. In the fourth group $(n=5), \mathrm{C} 4-\mathrm{C} 6$ and C8-T2 roots were cut, leaving $\mathrm{C} 7$ intact for 1 week (leading to degeneration of all centrally projecting branches of the injured roots). After 1 week, the $\mathrm{C} 7$ root was cut and allowed to reanastomose without the use of adhesive or sutures concomitantly with initiation of NT-3 treatment. All NT-3 treatments lasted for 1 week.

All surgical procedures were performed under sodium pentobarbital anesthesia (45 mg/kg, i.p.). The left side of the dorsolateral cervical spinal cord was exposed from $\mathrm{C} 4$ to $\mathrm{T} 2$ by removing a small piece of each vertebra, just medial to the articulating processes. Small slits in the dura mater allowed insertion of either fine forceps or small iris scissors to crush (control group) or cut (experimental groups) dorsal roots midway between the DRG and the DREZ ( $\sim 2.5 \mathrm{~mm}$ from each). In the experimental (treated) groups, cut roots were allowed to reanastomose without sutures or adhesives. In the control (untreated) group, C4-T2 roots were crushed repeatedly (three times each, 10 sec per crush). Osmotic minipumps were prepared as described previously (Ramer et al., 2000): NT-3 mixed with rat serum albumin (RSA; $1 \mathrm{mg} / \mathrm{ml}$ ) was delivered into the CSF via a catheter, which was inserted through the atlanto-occipital membrane, and whose tip rested between the C6 and C7 DREZ. The NT-3 delivery rate was $12 \mu \mathrm{g} / \mathrm{d}$, and the delivery duration in all cases was $7 \mathrm{~d}$. At the time of injury, the median nerve was injected with $1 \mu \mathrm{l}$ of $1 \%$ cholera toxin B fragment (CTB) in distilled water, via a glass pipette glued to a Hamilton syringe.

Immunohistochemistry. Rats were perfusion-fixed through the aorta with $4 \%$ paraformaldehyde, and cervical spinal cords, DRG, and brainstems were removed. The tissue was post-fixed for $1-3 \mathrm{hr}$ in the same fixative, cryoprotected in $20 \%$ sucrose in $0.1 \mathrm{M}$ phosphate buffer, and frozen in O.C.T. compound over liquid nitrogen. Twenty-micrometerthick transverse sections of spinal cord (C7) and brainstem (at the level of the main and external cuneate nuclei) were cut on a cryostat and processed immunohistochemically for CTB (1:2000; host goat, Quadratech), astrocytic glial fibrillary acidic protein (GFAP; 1:3000; host rabbit; Dako, Bucks, UK), or the macrophage marker ED1 (1:500; host mouse; Sigma, Gillingham, UK). After incubation in $10 \%$ normal donkey serum (in $0.1 \mathrm{M}$ PBS, $0.2 \%$ Triton $\mathrm{X}-100$, and $0.1 \%$ sodium azide), sections were exposed to primary antibodies overnight. After washing, secondary antibodies raised in donkey and conjugated to either tetramethylrhodamine, fluorescein, or aminomethylcoumarin were applied for $2 \mathrm{hr}$ (1:200; all from Jackson ImmunoResearch, West Grove, PA). After a final wash, slides were coverslipped and viewed with a Leica fluorescence microscope with a standard filter set. DRG were cut at $15 \mu \mathrm{m}$ and doubly processed immunohistochemically to visualize the growth-associated protein GAP-43 (1:3000; host rabbit; a gift from E. Wilkin) and the nonselective neuronal marker $\beta$ III-tubulin (host mouse; $1: 1000$; Promega, Southampton, UK). The GAP-43 antibody has been well characterized previously (Stewart et al., 1992).

Image analysis. All image analysis was done using SigmaScan Pro 4 software (SPSS) on images of the DRG or spinal cord around the entry zone captured with a Hamamatsu digital camera. Axonal regeneration into the CNS was quantified densitometrically: a threshold was applied to each of three nonadjacent images from each animal, and the axonal density was determined as a function of distance centrally from the apex of the dorsal root entry zone. In this way the density profile and maximum regeneration distance could be determined. In cases in which injured $\mathrm{C} 4-\mathrm{C} 6$ and $\mathrm{C} 8-\mathrm{T} 2$ axons projecting in the cuneate fasciculus were allowed to degenerate for 1 week before cutting the $\mathrm{C} 7$ root, axon densities were measured on either side of the boundary between the CNS part of the root and the cuneate fasciculus (easily visible with a GFAP stain). Astrocytic and macrophage responses were also determined densitometrically, by measuring the proportional area occupied by GFAP or
ED1 immunoreactivity in the white matter of the root or cuneate fasciculus or the dorsal horn gray matter.

Nucleated profiles of all DRG neurons ( $\beta$ III-tubulin-labeled) from three randomly selected sections from each animal were traced onscreen. The resulting drawn layer was then used to determine the proportion, size distribution, and staining intensity of GAP-43-labeled profiles in the same double-labeled sections. In each section, a threshold value (gray level) for positivity was determined empirically by averaging the intensity of three "minimally positive" (i.e., non-negative) profiles. DRG analysis was done blind.

Results were compared using one-way ANOVAs, unless otherwise indicated.

\section{RESULTS}

\section{Regeneration across the DREZ}

In untreated animals that received a septuple crush rhizotomy (C4-T2) 1 week before killing, axons transganglionically labeled with the B fragment of cholera toxin (CTB) invariably failed to penetrate the DREZ, and many swollen axon endings were apparent on the PNS side (Fig. $1 A$ ).

As we have described previously (Ramer et al., 2000), immediate NT-3 treatment promoted the ingrowth of CTB-labeled axons throughout the DREZ and into the spinal cord: after 1 week of treatment, cut dorsal root axons extended through the white matter portion of the root (the border of which was identified with the astrocytic marker GFAP), and into the cuneate fasciculus as well as the superficial part of the dorsal horn (Fig. $1 B)$. At this time point, axons had grown centrally as far as $1 \mathrm{~mm}$ from the apex of the entry zone (Fig. $1 F$ ), and few swollen end bulbs were observed at the entry zone or within the spinal cord (Fig. $1 B, D$ ). It should be noted that not all labeled axons that reached the entry zone were able to cross with NT-3 treatment (the axonal density in the PNS side of the DREZ is clearly greater than that on the CNS side). However, CTB labels myelinated GM-1 ganglioside-expressing neurons (small and large), which accounts for $\sim 45 \%$ of all somatic afferents (Tong et al., 1999). TrkC-expressing neurons are nearly exclusively large in diameter and account for $\sim 25 \%$ of all DRG neurons (McMahon et al., 1994). Therefore, only 50-60\% of CTB-labeled neurons should be responsive to NT-3 and might be expected to grow across the DREZ.

With delayed NT-3 treatment, the extent of growth and axonal morphology were distinctly different from the immediately treated group (Fig. 1C,E). CTB-labeled fibers entered the CNS portion of the root, but did not travel very far before either forming dystrophic end bulbs or coiling around empty spaces (presumably blood vessels) (Fig. $1 E$, arrow). Although there was no extension of neurites from the central portion of the root into the cuneate fasciculus after delayed treatment, where there was a short distance between the DREZ and the dorsal horn (near the rostral or caudal limit of each rootlet) some axons did extend into the gray matter (see Figs. 4, 5). If NT-3 treatment was delayed for 2 weeks, the axonal ingrowth beyond the DREZ was even more restricted (data not shown).

In all of the animals included in this study, a lack of terminal labeling in the cuneate nucleus indicated that both crush (control) and cut (experimental) dorsal root lesions resulted in complete removal of afferent input from the rhizotomized segments.

\section{Cell body reaction}

Because NT-3 activates TrkC receptors, expressed on large diameter sensory neurons (McMahon et al., 1994), we hypothesized that the growth-promoting effect of NT-3 would involve an increased cell body response to rhizotomy. One aspect of the cell 

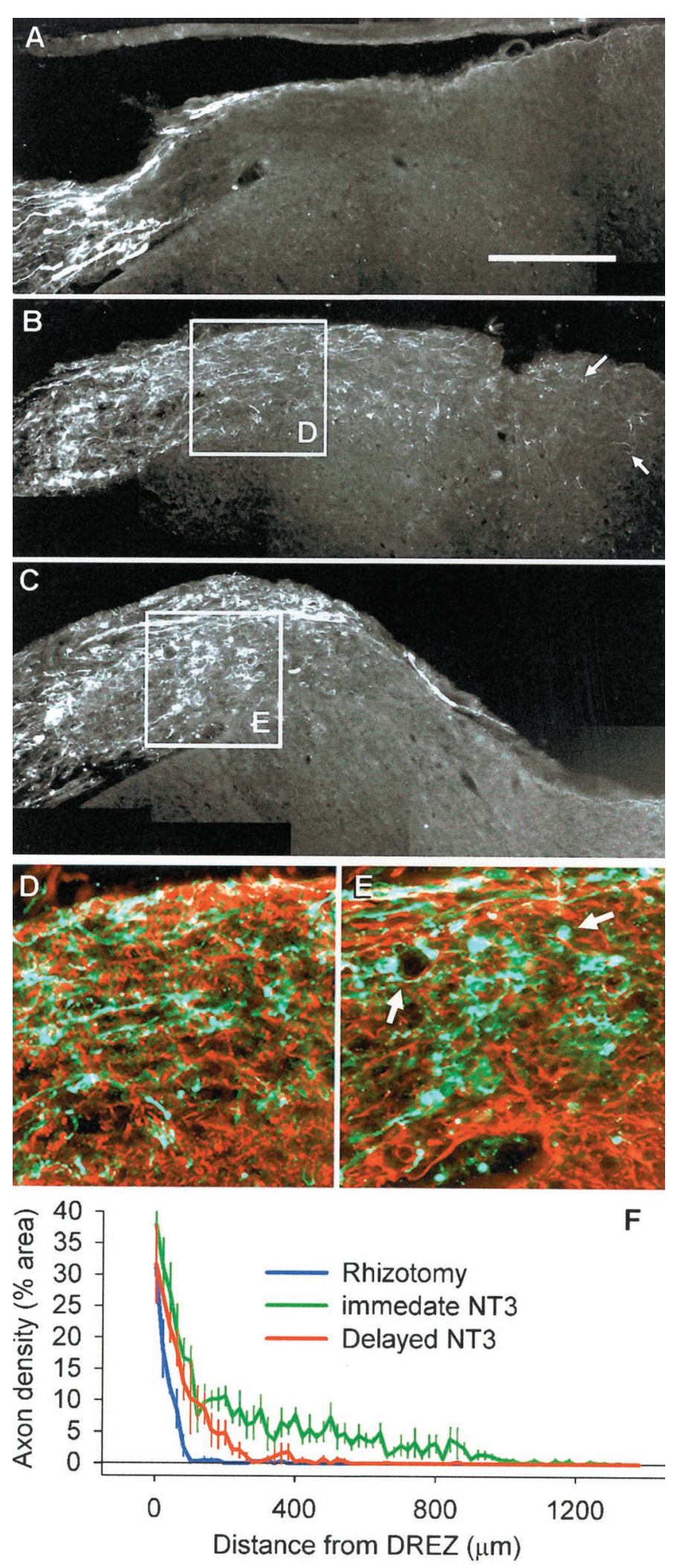

Figure 1. Axon growth across the DREZ. A, Regenerating CTB-labeled dorsal root axons grow within the peripheral part of the root, but halt on contact with the astrocytic boundary at the DREZ and do not penetrate the CNS part of the root, the cuneate fasciculus, or the dorsal horn. $B$, Immediate NT-3 treatment results in ingrowth of injured axons across the DREZ and into the cuneate fasciculus and dorsal horn (arrows) by 1 week after lesion. $C$, Delaying NT-3 treatment results in abortive ingrowth: axons regenerate only a short distance across the DREZ and are mor- body response is the upregulation of GAP-43. In uninjured ganglia, a proportion of small to medium-sized cells constitutively express GAP-43 (Verge et al., 1990b; Andersen and Schreyer, 1999), although here we find GAP-43 expression in all sizes of DRG neurons (26\% of all profiles; $30 \%$ of profiles $>45 \mu \mathrm{m}$ in diameter) (Fig. $2 A$ ). Rhizotomy alone did not lead to a significant upregulation of GAP-43 (35\% of all profiles, $34 \%$ of profiles $>45$ $\mu \mathrm{m}$ in diameter; not significant) (Fig. $2 B, E, F)$, as reported previously by others (Chong et al., 1996), nor did NT-3 alone upregulate GAP-43, as determined from analysis of contralateral ganglia from treated animals (35\% of all profiles, $35 \%$ of profiles $>45 \mu \mathrm{m}$ in diameter, not significant) (Fig. 2E,F). However, rhizotomy plus immediate NT-3 treatment resulted in a significant upregulation of GAP-43 (46\% of all profiles, $53 \%$ of profiles $>45 \mu \mathrm{m}$ in diameter; $p<0.05$ ) (Fig. $2 B, E, F)$, and this occurred primarily in large-diameter neurons (Fig. $2 E, F, G$ ), consistent with a specific effect of NT-3 on this population of cells.

One possibility for the abortive ingrowth after delayed treatment is that rhizotomy plus NT-3 failed to induce an appropriate cell body response in DRG neurons whose axons have already reached the entry zone. Cai et al. (1999) have shown that previous exposure of DRG neurons to MAG prevents neurotrophic factor treatment from promoting neurite extension in vitro. However, the GAP-43 upregulation by rhizotomy plus delayed NT-3 was equivalent to that produced by rhizotomy plus immediate NT-3 (47\% of all profiles, $46 \%$ of profiles $>45 \mu \mathrm{m}$ in diameter) (Fig. 2D-G), suggesting that whether axons reach the entry zone before or after being treated with NT-3 has no impact on at least this aspect of the cell body reaction to injury.

\section{Non-neuronal cell responses}

Because GAP-43 induction in response to rhizotomy plus NT-3 treatment is identical in immediately and belatedly treated rats, we were interested in determining whether the abortive ingrowth observed in the latter group was associated with non-neuronal cell responses to axotomy such as astrogliosis and phagocytic cell responses associated with Wallerian degeneration.

During the early postnatal period, astrocytes migrate into the dorsal root from the spinal cord giving rise to a cone-shaped protrusion of CNS in the proximal part of the dorsal root (Fig. $3 A$ ). Rhizotomy gives rise to a gliotic response involving proliferation and hypertrophy of astrocytes in the CNS portion of the root as well as the dorsal gray matter (Liu et al., 1998). Additionally, glial processes extend into the dorsal root for many tens of micrometers (Fig. 3B,C). GFAP area fraction measurements indicated that the hypertophy/proliferation response were well underway in both the white (from $7 \%$ in intact cords to $21 \%$ of total area after rhizotomy) and gray (from 3 to $10 \%$ ) matter by 1 week after rhizotomy, at the time of killing of the immediately treated rats (Fig. 3D), but were increased further 1 week later, at the time of killing of the belatedly treated rats.

phologically different from those in immediately treated rats. $D$, Axon growth central to the DREZ in immediately treated rats appears relatively unidirectional and uninterrupted (enlarged from B) (green, CTB; red, GFAP). E, After delayed treatment, axons are impeded such that they form ring-like structures and dystrophic end bulbs (arrows) (enlarged from $C) . F$, Quantification of axon density central to the DREZ (mean \pm SEM) shows that there is a large difference in the distance that axons penetrate the cord. Immediate NT-3 results in the furthest growth, delayed NT-3 treatment results in abortive ingrowth, and without treatment there is no ingrowth. Scale bar: $A, 250 \mu \mathrm{m}$. 

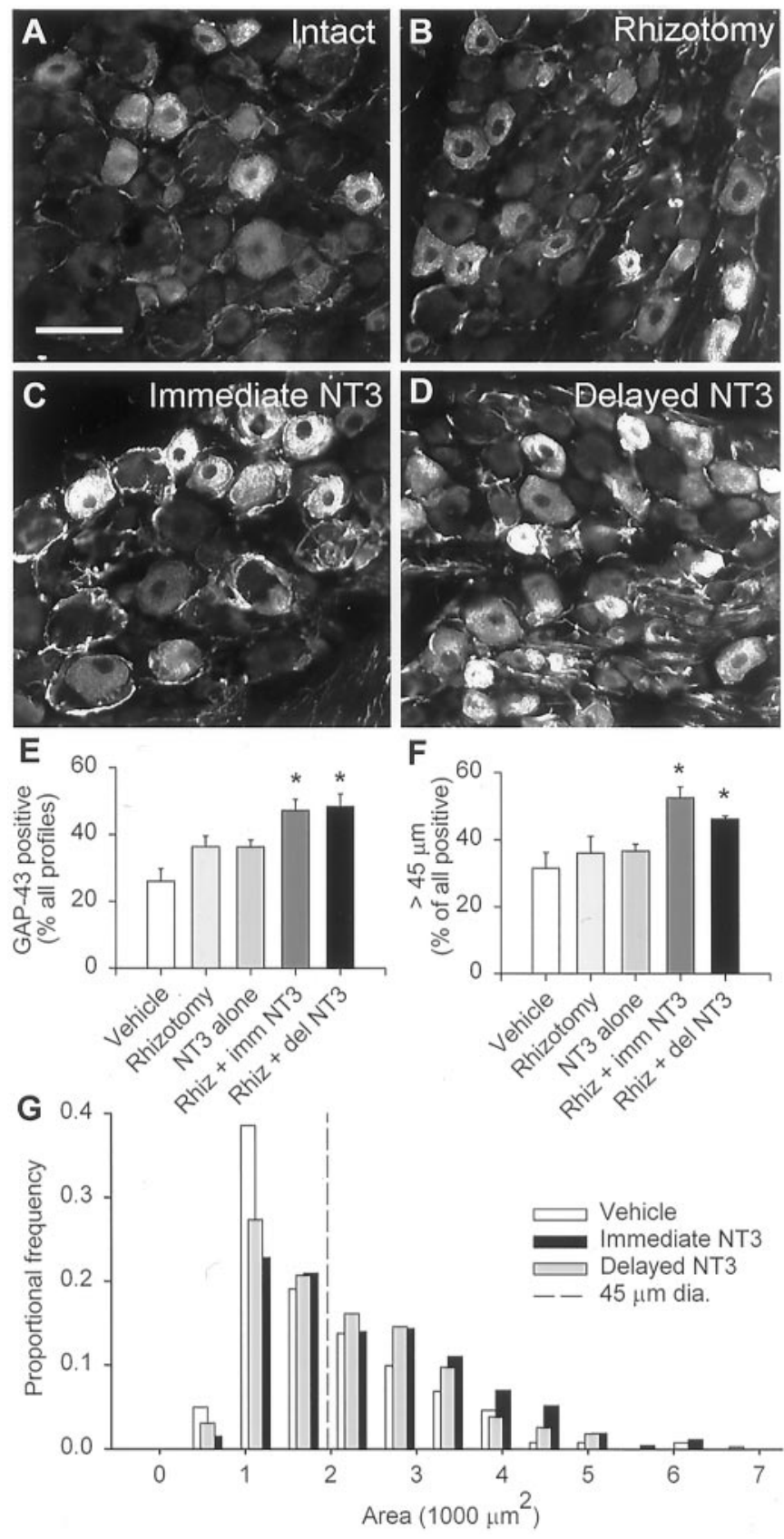

Figure 2. GAP-43 immunohistochemistry. A, A subpopulation of smallto medium-sized DRG neurons constitutively expresses GAP-43. B, Dorsal rhizotomy leads to no significant increase in the proportion of labeled cells. $C, D$, Immediate and delayed NT-3 treatment leads to increases in the proportion and labeling intensity of GAP-43-positive neurons. E, A significant increase in the proportion of GAP-43-positive cells occurs only when rhizotomy and NT-3 treatment (immediate or delayed) are combined. $F$, Of the GAP-43-positive neurons, there is an increase in the proportion of medium to large cells $(>45 \mu \mathrm{m})$ in the NT-3-treated rhizotomized groups only. $G$, Size distribution of GAP-43-positive neurons, showing that the increase in proportion of GAP-43-positive cells involves mainly the medium- to large-diameter profiles. Asterisks indicate significant differences from vehicle-treated, uninjured DRGs (one-way ANOVA, Tukey's post hoc test). Scale bar: $A, 100 \mu \mathrm{m}$.

Wallerian degeneration is associated with the presence within nervous tissue of activated blood-derived and resident phagocytic cells. In the PNS, ED1 is expressed by activated macrophages, whereas in the CNS activated microglia are the main expressers of this antigen (Brierley and Brown, 1982a,b; Perry et al., 1987). Under normal circumstances there is very little, if any ED1 immunoreactivity anywhere around the DREZ (Fig. 3E). One week after rhizotomy, there was a massive infiltration of the dorsal root by macrophages (50\% of total area occupied by ED1 immunoreactivity), but there was little ED1 expression central to the DREZ (1\% area) (Fig. 3F,H). Two weeks after rhizotomy, significant increases in ED1 immunoreactivity were observed in the CNS part of the root as well as the cuneate fasciculus (to $38 \%$ ), but not in the dorsal horn (Fig. $3 G, H$ ), in agreement with previous studies (Liu et al., 1998). Figure 4 shows the relationship between regenerating CTB-labeled axons and ED1 immunoreactivity in the spinal cord after immediate and delayed NT-3 treatment. The axonal coils do not associate specifically with, nor do the dystrophic end bulbs appose, ED1-positive structures, suggesting that it is a product of phagocyte invasion, rather than phagocytic cells per se, that is causing the abortive regeneration.

Neither the gliotic (GFAP) nor the degenerative (ED1) reactions were affected significantly by intrathecal NT-3 treatment (Fig. 3D,H), indicating that an altered response of non-neuronal cells in NT-3-treated animals does not underlie NT-3-promoted axonal ingrowth.

\section{Cord predegeneration}

The above results show that under the influence of NT-3, regenerating axons can grow through an environment consisting of proliferating activated astrocytes, but not through CNS tissue undergoing frank degeneration, because delaying NT-3 treatment and allowing Wallerian degeneration within the CNS white matter to progress resulted in abortive ingrowth. To test this hypothesis, we cut and resected the $\mathrm{C} 4-\mathrm{C} 6$ and $\mathrm{C} 8-\mathrm{T} 2$ roots (preventing regeneration) 1 week before cutting the $\mathrm{C} 7$ root and allowing it to re-anastomose. Intrathecal NT-3 treatment commenced along with the $\mathrm{C} 7$ rhizotomy. This procedure results in the "predegeneration" of ascending and descending collaterals within the cuneate fasciculus, but not within the CNS portion of the spared C7 root. Thus, at the time of killing, axons in the cuneate fasciculus will have been axotomized for 2 weeks, but those in the central part of the C7 root will have only been injured for 1 week.

Under these conditions we found that the pattern of axon growth within the CNS part of the C7 root was identical to that after rhizotomy plus immediate NT-3 treatment (Fig. $5 B$ ): the trajectories of the regenerating axons were more or less uninterrupted, and axons frequently entered the dorsal gray matter. However, unlike in the immediately treated group, few or no axons grew into the degenerating cuneate fasciculus (Fig. $5 B, E, F)$. This result indicates that even when injured dorsal root axons are treated with NT-3 before exposure to CNS material at the DREZ, they still fail to penetrate white matter undergoing advanced (2 weeks) degeneration.

\section{Pattern of continued growth}

Axons continue to grow in the spinal cord beyond 2 weeks with sustained neurotrophic factor treatment (Ramer et al., 2000). How do they do so if the degenerating environment (which becomes well established between 1 and 2 weeks after lesion) is so inhospitable? Parasaggital sections of cord from uninjured rats shows the normal distribution of CTB-labeled axons within lamina I and III, but not in lamina II (Fig. 6). In immediately treated rats 2 weeks after rhizotomy, regenerated axons are primarily situated along the pial surface (possibly responding to a tropic influence of NT-3), and within lamina II, normally devoid of 

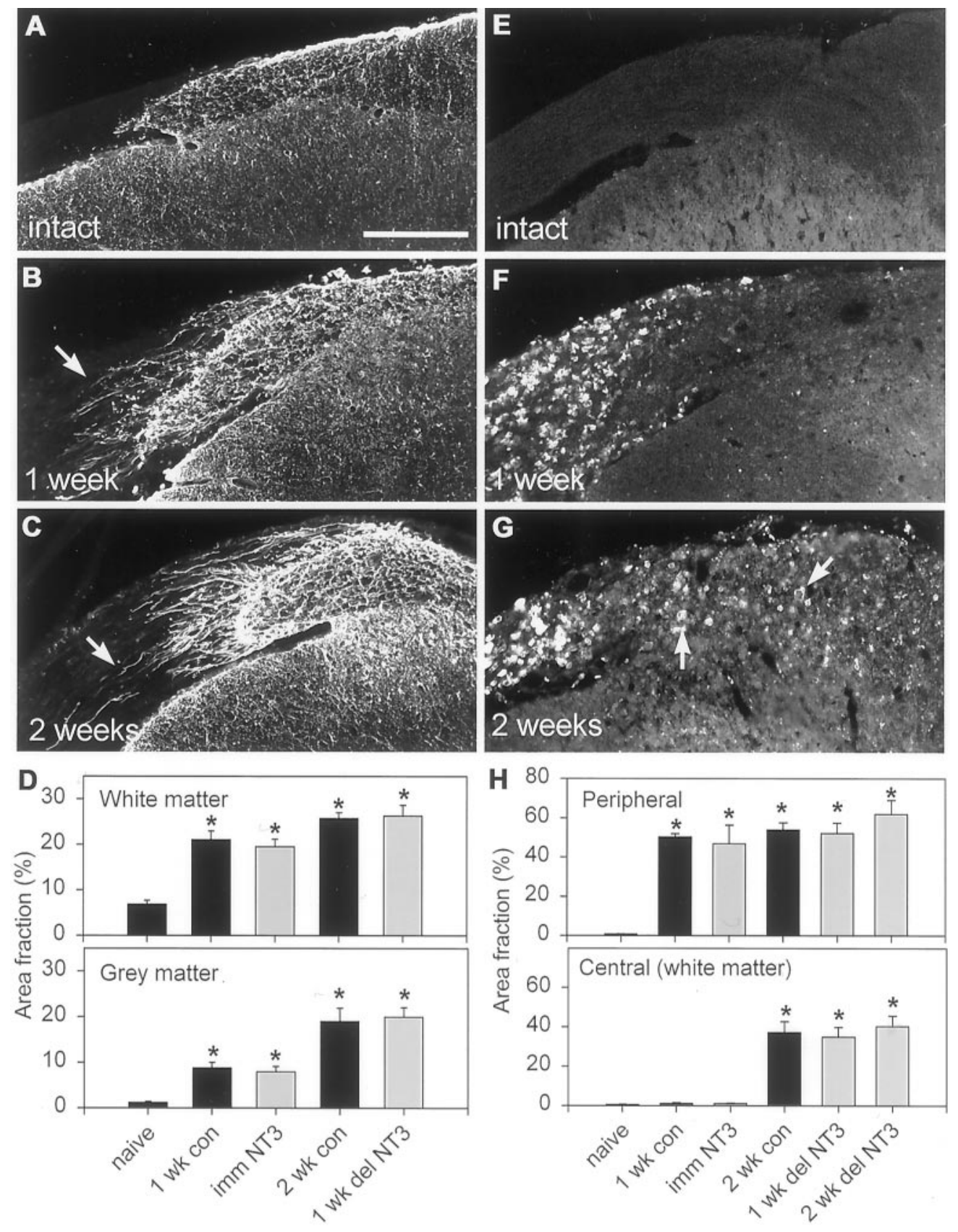

Figure 3. GFAP and ED-1 immunoreactivity after dorsal rhizotomy. $A$, GFAP is expressed by CNS astrocytes and is normally absent from the dorsal root. $B, C$, GFAP expression increases within the first few days postoperatively and is well advanced by $1(B)$ and $2(C)$ weeks after rhizotomy. Fine astrocytic processes have extended into the injured root (arrows). D, Quantification of GFAP-positive area fraction in white and gray matter (mean \pm SEM). Gray matter astrogliosis lags slightly behind white matter astrogliosis. There is no significant difference between untreated (black bars) and NT-3-treated rats (gray bars). E, ED-1 immunoreactivity is absent from all areas surrounding the entry zone in naive animals. $F$, By 1 week after rhizotomy, ED-1positive cells (macrophages) have invaded the degenerating dorsal root but are still absent from the CNS. $G$, Two weeks after rhizotomy, ED-1-positive cells (macrophages and microglia) are present within the CNS portion of the dorsal root and the dorsal columns (arrows) but remain absent from the gray matter. $H$, Quantification of ED-1 immunoreactivity (area fraction) peripheral and central to the DREZ (mean \pm SEM). NT-3 (gray bars) has no effect on ED-1 immunoreactivity. Asterisks in D and $H$ indicate significant increases compared with naïve. Scale bar, $250 \mu \mathrm{m}$. these axons (Fig. 6B,E). Relatively few axons can be seen in the intervening white matter (Fig. 6B,E,F). This shows that once within the spinal cord, axons regenerating under the influence of NT-3 favor the dorsal gray matter as a substrate for growth over the degenerating white matter tracts, as others have previously suggested in tissue culture experiments (Savio and Schwab, 1989).

\section{DISCUSSION}

Delaying NT-3 treatment significantly compromised axon ingrowth across the DREZ. This was not caused by a subdued GAP-43 upregulation after delayed versus immediate treatment but by the relative timing of axonal contact with the DREZ and non-neuronal events in the cord. Dorsal roots regenerate at a rate of 2-2.5 mm/d (Wujek and Lasek, 1983; Oblinger and Lasek, 1984; Richardson and Verge, 1986), hence most axons would have reached the DREZ by $3 \mathrm{~d}$ after lesion. Astrocytic hypertrophy and proliferation are well underway by $2 \mathrm{~d}$ after injury (Liu et al., 1998). However, outright degeneration (implicit in the appearance of ED1-positive cells) does not begin until after the first postoperative week. Therefore glial reactions to rhizotomy are separated chronologically, and the relative potency of inhibitory barriers at the DREZ can be determined. The reactive astroglial environment permits regeneration if neurons are encouraged with NT-3. However, if NT-3-treated axons encounter a CNS environment undergoing advanced degeneration, regeneration is abortive. Beyond this time point regeneration can continue, but in more permissive gray matter.

\section{Barrier one: astrocytes}

The major cell type in the CNS is astrocytes. These cells form the glia limitans, covering the entire surface of the CNS, and separating PNS and CNS dorsal root compartments (Thomas et al., 

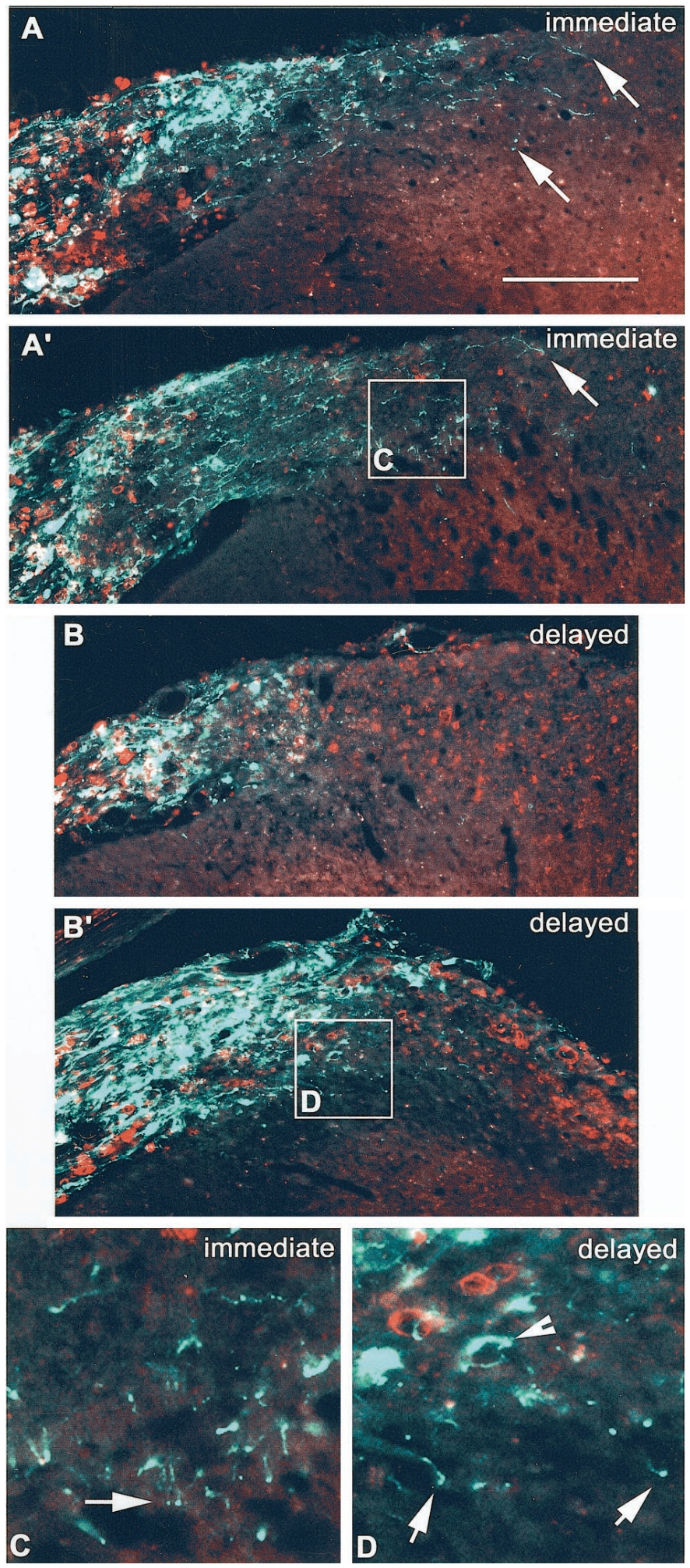

Figure 4. The relationship between ED-1 expression (red) and CTBlabeled sensory axon ingrowth (green). $A, A^{\prime}$, Two examples from different animals treated immediately with NT-3 on rhizotomy. Axons have extended well beyond the dorsal root into the central part of the root, the cuneate fasciculus, and into the dorsal horn (arrows). $B, B^{\prime}$, Two examples from different animals treated with NT-3 starting 1 week after rhizotomy. Axons barely penetrate the DREZ and do not travel lateromedially. However, some axons penetrate the superficial layers of the dorsal horn. $C$, Enlarged from box in $A^{\prime}$, showing axons crossing from the white matter into the dorsal horn. Arrow shows regenerating axons superficial laminae. $D$, Enlarged from box in $D$, showing ED-1 immunoreactivity in the
1993; Fraher, 2000). Astrocytes are not always inhibitory to neurite elongation: in vitro and in vivo studies show that the embryonic or early postnatal DREZ is permissive (Carlstedt et al., 1987; Golding et al., 1996, 1999). However, that astrocytes are normally inhibitory is obvious from the fact that all regenerating axons stop on contact with them.

The molecular nature of astrocytic inhibition is unclear, but chondroitin sulfate proteoglycans (CSPGs) in the extracellular matrix are probably major players (Fawcett and Asher, 1999). CSPG disruption in three-dimensional astrocyte cultures or on cryosections of adult spinal cord increases axonal elongation (Smith-Thomas et al., 1995; Zuo et al., 1998b). Spinal CSPG expression begins during the first postnatal week, coinciding perfectly with the end of the permissive period of the DREZ (Pindzola et al., 1993), and dorsal rhizotomy further upregulates CSPG expression (Pindzola et al., 1993; Zhang et al., 1999). Direct lesions to the CNS induce CSPG deposition at the lesion site, which halts the axonal progress of transplanted DRG neurons (Davies et al., 1997, 1999). The extent to which the astrocytic reaction at the DREZ mimics that after CNS lesions is unknown, but in addition to proliferation of astrocytes, oligodendrocyte precursors, and microglia (Liu et al., 1998; Fawcett and Asher 1999), common features include increased NG2 expression by glial cells (Dou and Levine, 1994; Levine, 1994; Zhang et al., 1999) and upregulation of tenascin-C and tenascin-R (Zhang et al., 1997, 1999; Fawcett and Asher, 1999), glycoproteins that bind many CSPGs and myelin-associated glycoprotein (MAG) in the extracellular matrix (Rauch et al., 1997; Yang et al., 1999).

\section{NT-3-mediated bypassing of barrier one}

The mechanism by which NT-3 promotes growth of sensory axons through the astrogliotic environment is also unclear, but indirect effects are unlikely: first, NT-3 selectively promotes ingrowth of large-diameter axons (90\% of which express trkC; McMahon et al., 1994) across the DREZ (Ramer et al., 2000), and here we found that a combination of rhizotomy plus NT-3 treatment selectively upregulated GAP-43 in large-diameter DRG neurons; second, intrathecal NT-3 infusion had no effect on the astrogliotic response or the appearance of ED1-expressing cells in the cord (Fig. 3).

Those DRG neurons that constitutively express GAP-43 regenerate as fast as peripherally transected axons (Andersen and Schreyer, 1999). Perhaps NT-3 accelerates regeneration within the root, resulting in the arrival of dorsal root axons at the DREZ before astrogliosis is full blown. However, constitutively GAP43-expressing neurons fail to regenerate across the DREZ in the absence of treatment, suggesting that earlier arrival is not key to regeneration across this barrier. What is the mechanism for NT-3-promoted ingrowth? NT-3 may upregulate specific enzymes that have the ability to degrade the extracellular matrix secreted by reactive astrocytes. Matrix metalloproteinases (MMPs) degrade CSPGs and enhance peripheral nerve regeneration (Zuo et al., 1998b). Sensory axon growth in vitro is enhanced by NGF, an effect mediated by MMP-2 (Muir, 1994). Whether NT-3 has a similar effect is unknown. Alternately, NT-3-treated neurons might upregulate receptors for growth-

\section{$\leftarrow$}

degenerating white matter (asterisks), and axons penetrating the dorsal horn (arrow). Arrowheads show dystrophic end bulbs and ring-like structures. Note the lack of association of the ring with ED-1 immunoreactivity. Scale bar: $A, 300 \mu \mathrm{m}$. 

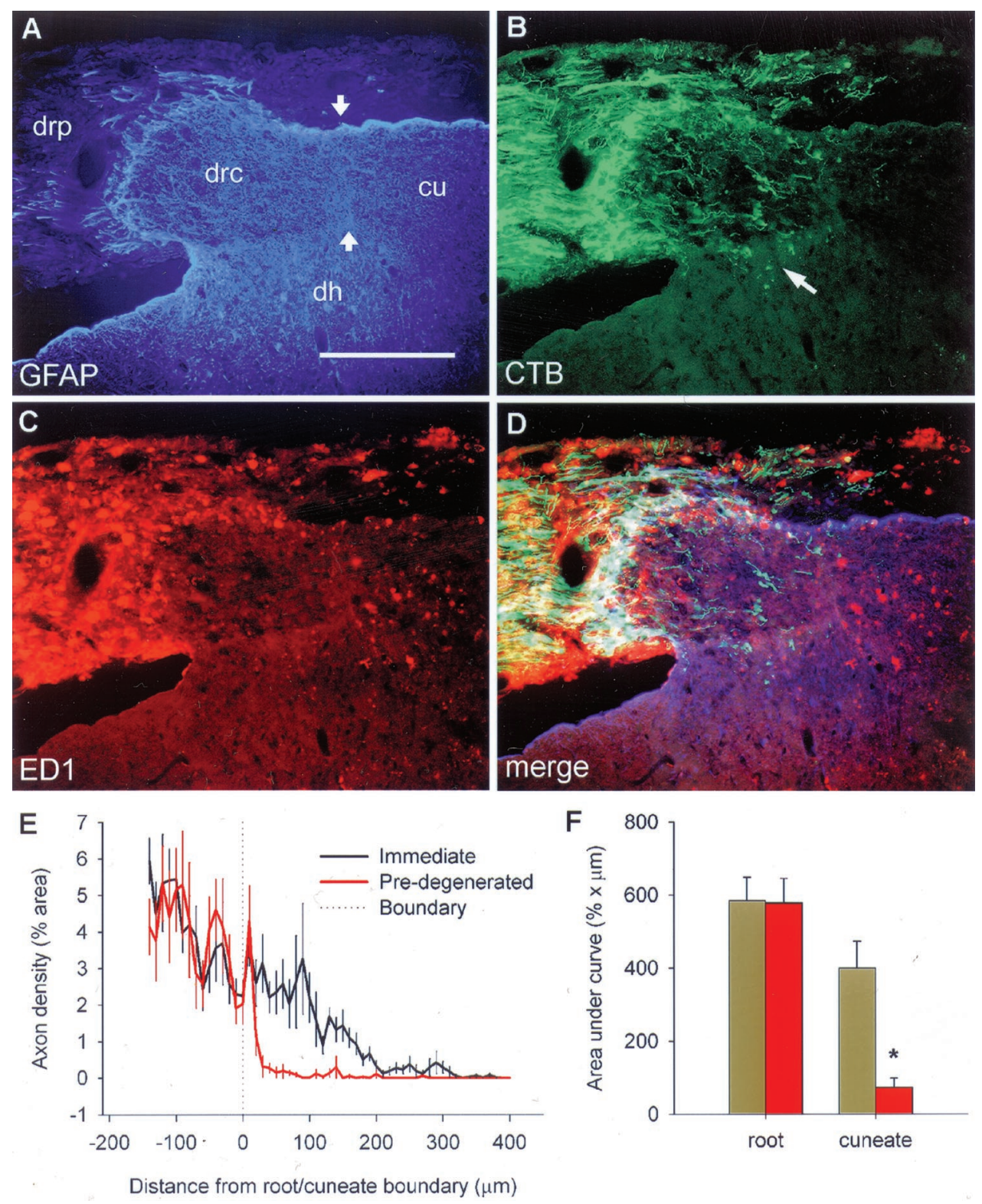

Figure 5. The state of degeneration dictates regenerative success. Images are from a single section taken from a rat that had received a dorsal root resection of $\mathrm{C} 4-\mathrm{C} 6$ and $\mathrm{C} 8-\mathrm{C} 2$, sparing $\mathrm{C} 7$ for 1 week. The $\mathrm{C} 7$ root was cut and allowed to reanastomose 1 week after the initial surgery, an NT-3 pump was implanted, and the rat survived for a further week. $A$, GFAP immunohistochemistry, showing the relationship between the peripheral and central parts of the dorsal root $(d r p, d r c)$, the dorsal horn $(d h)$, and cuneate fasciculus $(c u) . B$, CTBlabeled axon ingrowth occurs as it does after immediate NT-3 treatment within the central part of the root (which has been degenerating for 1 week), but fails to penetrate the degenerating cuneate fasciculus (which has been degenerating for 2 weeks). Arrow indicates axon growth into the dorsal horn. $C$, ED-1 immunohistochemistry showing heavy invasion of the peripheral nerve and cuneate fasciculus by phagocytic cells, but with a lack of ED-1 staining in the central part of the root into which axons have regenerated. $D$, Merged images. $E$, Mean \pm SEM axon density either side of the border between the central part of the dorsal root and the cuneate fasciculus $(A$, arrows). $F$, Area under the curves in $D$ showing a significant failure of axons to penetrate the degenerating cuneate fasciculus. Scale bar, $300 \mu \mathrm{m}$.

permissive elements of the extracellular matrix. Embryonic DRG neurons will grow across the adult DREZ in vitro and in vivo (Rosario et al., 1992; Kozlova et al., 1994; Golding et al., 1996, 1999), possibly the result of increased laminin-binding integrin expression by the embryonic neurons (Condic et al., 1999). NGF increases the expression of integrins in PC-12 cells and causes their accumulation in sympathetic growth cones (Rossino et al., 1990; Zhang et al., 1993; Grabham and Goldberg, 1997). Again, whether NT-3 has a similar effect remains to be seen. A third possibility is that NT-3 decreases the expression of receptors for unidentified astrocyte-derived inhibitory signals expressed at the DREZ.

\section{Barrier two: Frank degeneration}

One finding of this study is that degenerating zones within the cord are a more formidable obstruction to axonal growth than astrogliotic zones. While able to grow among intact myelin sheaths, NT-3-treated axons failed to grow in CNS areas into which ED1-expressing cells had infiltrated. Two weeks after rhizotomy, these included the white matter portion of the root and the cuneate fasciculus, but not the dorsal horn. The invasion of the central dorsal root compartment by ED1-expressing cells is not only associated with the beginning of myelin breakdown, but also with an increase in the expression of CSPGs (Fitch and Silver, 1997), an effect that may contribute to the second regenerative barrier.

Migration into the peripheral compartment by phagocytic cells is associated with rapid myelin removal (complete by $30 \mathrm{~d}$ after rhizotomy), but myelin clearance in the CNS is much more protracted (George and Griffin, 1994). Failure of myelin clearance probably results from the lack of induction of the complement system (Liu et al., 1998): peripherally, complement attracts and activates phagocytes (Bruck and Friede, 1991). Specific removal of myelin with complement and galactocerebroside antibodies resulted in the regeneration of some axons within the cord (Keirstead et al., 1995; Dyer et al., 1998). Immunization of mice against myelin can likewise result in long-distance regeneration of descending tracts (Huang et al., 1999).

There are two strong oligodendrocyte-derived molecular can- 

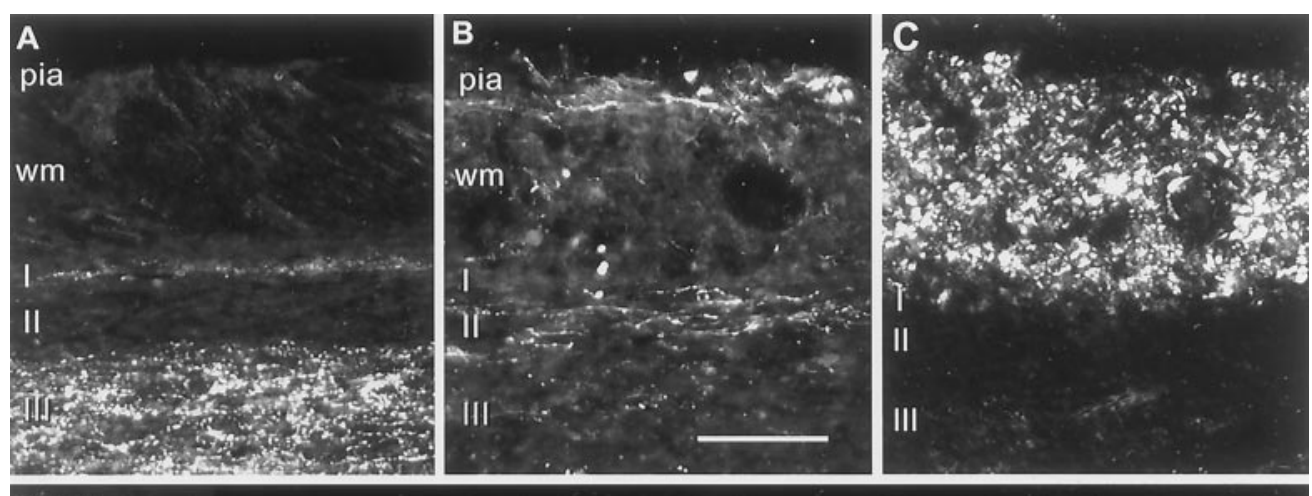

Figure 6. Axon growth 2 weeks after
rhizotomy plus immediate NT-3 treatment. $A$, In intact animals, CTBlabeled terminals are present in lamina I and III, but absent from lamina II. $B$, Regenerating axons grow along the pial surface of the cord and in the superficial laminae of the gray matter, avoiding the degenerating cuneate fasciculus. $C$, Dark-field micrograph of $B$. Scale bar: $B, 100 \mu \mathrm{m}$. D, Dark-field parasaggital section from a 2 week rhizotomized and NT-3-treated rat. E, Same section as in $D$, immunostained for CTB. CTB-labeled axons can be seen on the pial surface (arrowheads) and within the cord. Many axons have turned to grow in a rostrocaudal direction but appear to do so in the superficial laminae of the gray matter rather than the white matter. Some individual axons can be traced for up to $2 \mathrm{~mm}$. $F$, In zones in which the density of regenerated axons is greatest, they form a longitudinal bundle in the gray matter, with few axons in the more superficial white matter (arrows). G, Many axons possess terminal swellings that may be growth cones or termination bulbs. Scale bar: $E, 300 \mu \mathrm{m}$.
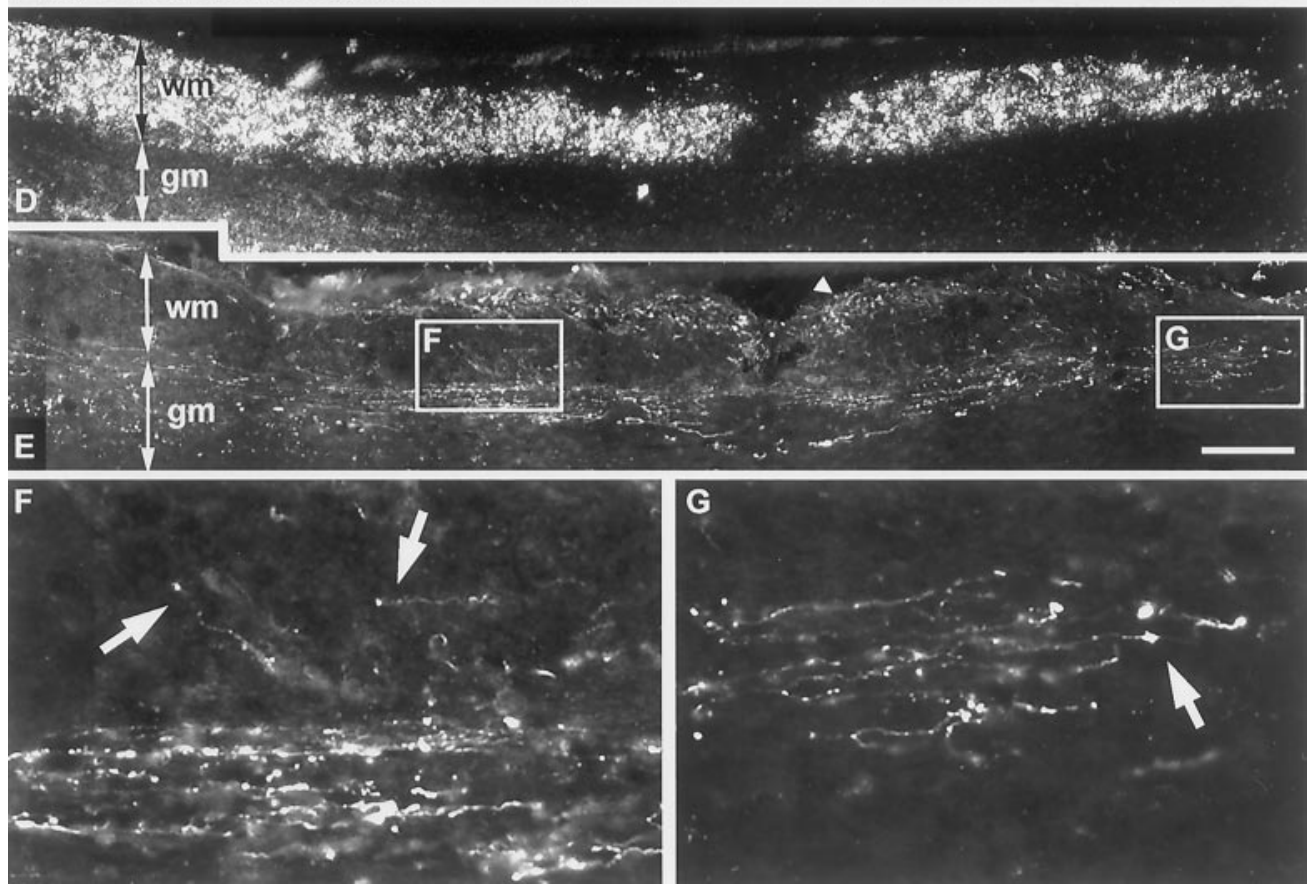

didates to mediate inhibition after delayed treatment. The first is MAG, which inhibits neurite outgrowth in vitro (Mukhopadhyay et al., 1994; Li et al., 1996; Tang et al., 1997). This inhibition is removed if DRG neurons are pretreated with neurotrophic factors, preventing a downregulation of cAMP that normally occurs in cultured DRG neurons on MAG exposure (Cai et al., 1999). In the present study, immediate NT-3 treatment axons were exposed to NT-3 before they reached the DREZ, whereas with delayed treatment, NT-3 was given after DREZ contact. Although this is consistent with the findings of Cai et al. (1999), when dorsal roots were severed and treated immediately with NT-3, they failed to penetrate white matter already undergoing frank degeneration, suggesting that if NT-3-elevated cAMP prevents the inhibitory effects of MAG, other molecules are even more potent.

The other major candidate is Nogo-A (Chen et al., 2000), which causes growth cone collapse in vitro. Neutralizing Nogo-A enhances regeneration of various systems in the CNS (Caroni and Schwab, 1988; Schnell and Schwab, 1990; Rubin et al., 1994; Z'Graggen et al., 1998; Buffo et al., 2000). Axons approaching degenerating zones are likely to be exposed to both MAG and Nogo-A.

The results presented here stand in stark contrast to experiments by Davies et al. (1999), in which dissociated adult mouse DRG neurons were implanted into previously injured dorsal columns in rats. Transplanted axons grew for long distances, only stopping on contact with the edge of the scar. One interpretation of these findings is that degenerating myelin is a less formidable barrier than the glial scar. Here we find the opposite order of inhibitory potency between astrogliotic and degenerative environments. There are several possible reasons for this disparity: first, manipulations associated with DRG dissociation and microinjection render the transplanted neurons less susceptible to inhibitory factors present in the degenerating dorsal columns; second, the different regenerative responses might relate to the amount of axon lost (in the Davies experiments all of the axon was removed). In several systems the regenerative response is augmented with increasing proximity of the lesion to the cell body (Mathew and Miller 1993; Fernandes et al., 1999). Other differences may include the differing glial elements encountered by regenerating axons along their course (after rhizotomy for example, axons must transit from Schwann cells to astrocytes), or temporal aspects: with delayed treatment, the axons would have been stopped for several days, possibly altering the extent to which they are capable of responding to NT-3 (although the equivalent upregulation of GAP-43 in immediately and belatedly treated rats would suggest otherwise).

Although neurotrophic factors show great promise for CNS regeneration, delaying treatment compromises regrowth across the DREZ. This finding reveals the relative importance of inhibitory influences faced by regenerating sensory axons. The most 
prominent inhibitory barrier is reflected in the appearance of ED1-expressing phagocytes, appearing after 1 week of rhizotomy and poorly traversed by NT-3-treated axons. The dorsal horn remains permissive to axon growth beyond the initiation of white matter degeneration. The lesser barrier is the astrogliotic environment present at the DREZ after rhizotomy, which does not normally permit regeneration, but succumbs to NT-3 treatment.

\section{REFERENCES}

Andersen LB, Schreyer DJ (1999) Constitutive expression of GAP-43 correlates with rapid, but not slow regrowth of injured dorsal root axons in the adult rat. Exp Neurol 155:157-164.

Bennett DL, French J, Priestley JV, McMahon SB (1996) NGF but not NT-3 or BDNF prevents the A fiber sprouting into lamina II of the spinal cord that occurs following axotomy. Mol Cell Neurosci 8:211-220.

Brierley JB, Brown AW (1982a) The origin of lipid phagocytes in the central nervous system: II. The adventitia of blood vessels. J Comp Neurol 211:407-417.

Brierley JB, Brown AW (1982b) The origin of lipid phagocytes in the central nervous system: I. The intrinsic microglia. J Comp Neurol 211:397-406

Bruck W, Friede RL (1991) The role of complement in myelin phagocytosis during PNS wallerian degeneration. J Neurol Sci 103:182-187.

Buffo A, Zagrebelsky M, Huber AB, Skerra A, Schwab ME, Strata P, Rossi F (2000) Application of neutralizing antibodies against NI-35/ 250 myelin-associated neurite growth inhibitory proteins to the adult rat cerebellum induces sprouting of uninjured Purkinje cell axons. J Neurosci 20:2275-2286.

Cai D, Shen Y, De Bellard M, Tang S, Filbin MT (1999) Prior exposure to neurotrophins blocks inhibition of axonal regeneration by MAG and myelin via a cAMP-dependent mechanism. Neuron 22:89-101.

Carlstedt T (1985) Regenerating axons form nerve terminals at astrocytes. Brain Res 347:188-191.

Carlstedt T, Dalsgaard CJ, Molander C (1987) Regrowth of lesioned dorsal root nerve fibers into the spinal cord of neonatal rats. Neurosci Lett 74:14-18.

Caroni P, Schwab ME (1988) Antibody against myelin-associated inhibitor of neurite growth neutralizes nonpermissive substrate properties of CNS white matter. Neuron 1:85-96.

Chen MS, Huber AB, van der Haar ME, Frank M, Schnell L, Spillmann AA, Christ F, Schwab ME (2000) Nogo-A is a myelin-associated neurite outgrowth inhibitor and an antigen for monoclonal antibody IN-1. Nature 403:434-439.

Chong MS, Woolf CJ, Turmaine M, Emson PC, Anderson PN (1996) Intrinsic versus extrinsic factors in determining the regeneration of the central processes of rat dorsal root ganglion neurons: the influence of a peripheral nerve graft. J Comp Neurol 370:97-104.

Chong MS, Woolf CJ, Haque NS, Anderson PN (1999) Axonal regeneration from injured dorsal roots into the spinal cord of adult rats. J Comp Neurol 410:42-54.

Condic ML, Snow DM, Letourneau PC (1999) Embryonic neurons adapt to the inhibitory proteoglycan aggrecan by increasing integrin expression. J Neurosci 19:10036-10043.

Davies SJ, Fitch MT, Memberg SP, Hall AK, Raisman G, Silver J (1997) Regeneration of adult axons in white matter tracts of the central nervous system. Nature 390:680-683.

Davies SJ, Goucher DR, Doller C, Silver J (1999) Robust regeneration of adult sensory axons in degenerating white matter of the adult rat spinal cord. J Neurosci 19:5810-5822.

Dou CL, Levine JM (1994) Inhibition of neurite growth by the NG2 chondroitin sulfate proteoglycan. J Neurosci 14:7616-7628.

Dyer JK, Bourque JA, Steeves JD (1998) Regeneration of brainstemspinal axons after lesion and immunological disruption of myelin in adult rat. Exp Neurol 154:12-22.

Eriksson NP, Lindsay RM, Aldskogius H (1994) BDNF and NT-3 rescue sensory but not motoneurones following axotomy in the neonate. NeuroReport 5:1445-1448.

Fawcett JW, Asher RA (1999) The glial scar and central nervous system repair. Brain Res Bull 49:377-391.

Fernandes KJ, Fan DP, Tsui BJ, Cassar SL, Tetzlaff W (1999) Influence of the axotomy to cell body distance in rat rubrospinal and spinal motoneurons: differential regulation of GAP-43, tubulins, and neurofilament-M. J Comp Neurol 414:495-510.

Fitch MT, Silver J (1997) Activated macrophages and the blood-brain barrier: inflammation after CNS injury leads to increases in putative inhibitory molecules. Exp Neurol 148:587-603.

Fraher JP (2000) The transitional zone and CNS regeneration J Anat [Erratum (1999) 194:161-182] 196:137-158.

Gavazzi I, Kumar RD, McMahon SB, Cohen J (1999) Growth responses of different subpopulations of adult sensory neurons to neurotrophic factors in vitro. Eur J Neurosci 11:3405-3414
George R, Griffin JW (1994) Delayed macrophage responses and myelin clearance during Wallerian degeneration in the central nervous system: the dorsal radiculotomy model. Exp Neurol 129:225-236.

Golding JP, Shewan D, Berry M, Cohen J (1996) An in vitro model of the rat dorsal root entry zone reveals developmental changes in the extent of sensory axon growth into the spinal cord. Mol Cell Neurosci 7:191-203.

Golding JP, Bird C, McMahon S, Cohen J (1999) Behaviour of DRG sensory neurites at the intact and injured adult rat dorsal root entry zone: postnatal neurites become paralysed, whilst injury improves the growth of embryonic neurites. Glia 26:309-323.

Grabham PW, Goldberg DJ (1997) Nerve growth factor stimulates the accumulation of beta1 integrin at the tips of filopodia in the growth cones of sympathetic neurons. J Neurosci 17:5455-5465.

Huang DW, McKerracher L, Braun PE, David S (1999) A therapeutic vaccine approach to stimulate axon regeneration in the adult mammalian spinal cord. Neuron 24:639-647.

Keirstead HS, Dyer JK, Sholomenko GN, McGraw J, Delaney KR, Steeves JD (1995) Axonal regeneration and physiological activity following transection and immunological disruption of myelin within the hatchling chick spinal cord. J Neurosci 15:6963-6974.

Kozlova EN, Stromberg I, Bygdeman M, Aldskogius H (1994) Peripherally grafted human foetal dorsal root ganglion cells extend axons into the spinal cord of adult host rats by circumventing dorsal root entry zone astrocytes. NeuroReport 5:2389-2392.

Lentz SI, Knudson CM, Korsmeyer SJ, Snider WD (1999) Neurotrophins support the development of diverse sensory axon morphologies. J Neurosci 19:1038-1048.

Levine JM (1994) Increased expression of the NG2 chondroitin-sulfate proteoglycan after brain injury. J Neurosci 14:4716-4730.

Li M, Shibata A, Li C, Braun PE, McKerracher L, Roder J, Kater SB, David S (1996) Myelin-associated glycoprotein inhibits neurite/axon growth and causes growth cone collapse. J Neurosci Res 46:404-414.

Lindsay RM (1996) Role of neurotrophins and trk receptors in the development and maintenance of sensory neurons: an overview. Philos Trans R Soc Lond B Biol Sci 351:365-373.

Liu L, Persson JK, Svensson M, Aldskogius H (1998) Glial cell responses, complement, and clusterin in the central nervous system following dorsal root transection. Glia 23:221-238.

Mathew TC, Miller FD (1993) Induction of T alpha 1 alpha-tubulin mRNA during neuronal regeneration is a function of the amount of axon lost. Dev Biol 158:467-474.

McMahon SB, Armanini MP, Ling LH, Phillips HS (1994) Expression and coexpression of Trk receptors in subpopulations of adult primary sensory neurons projecting to identified peripheral targets. Neuron 12:1161-1171.

Muir D (1994) Metalloproteinase-dependent neurite outgrowth within a synthetic extracellular matrix is induced by nerve growth factor. Exp Cell Res 210:243-252.

Mukhopadhyay G, Doherty P, Walsh FS, Crocker PR, Filbin MT (1994) A novel role for myelin-associated glycoprotein as an inhibitor of axonal regeneration. Neuron 13:757-767.

Munson JB, Shelton DL, McMahon SB (1997) Adult mammalian sensory and motor neurons: roles of endogenous neurotrophins and rescue by exogenous neurotrophins after axotomy. J Neurosci 17:470-476.

Oblinger MM, Lasek RJ (1984) A conditioning lesion of the peripheral axons of dorsal root ganglion cells accelerates regeneration of only their peripheral axons. J Neurosci 4:1736-1744

Ohara S, Tantuwaya V, DiStefano PS, Schmidt RE (1995) Exogenous NT-3 mitigates the transganglionic neuropeptide Y response to sciatic nerve injury. Brain Res 699:143-148.

Perry VH, Brown MC, Gordon S (1987) The macrophage response to central and peripheral nerve injury. A possible role for macrophages in regeneration. J Exp Med 165:1218-1223.

Pindzola RR, Doller C, Silver J (1993) Putative inhibitory extracellular matrix molecules at the dorsal root entry zone of the spinal cord during development and after root and sciatic nerve lesions. Dev Biol 156:34-48.

Ramer MS, Priestley JV, McMahon SB (2000) Functional regeneration of sensory axons into the adult spinal cord. Nature 403:312-316.

Ramon y Cajal S (1928) Degeneration and regeneration in the nervous system. New York: Hafner.

Rauch U, Clement A, Retzler C, Frohlich L, Fassler R, Gohring W, Faissner A (1997) Mapping of a defined neurocan binding site to distinct domains of tenascin-C. J Biol Chem 272:26905-26912.

Richardson PM, Verge VM (1986) The induction of a regenerative propensity in sensory neurons following peripheral axonal injury. J Neurocytol 15:585-594.

Rosario CM, Aldskogius H, Carlstedt T, Sidman RL (1992) Centrifugal growth in orthotopic grafts of allogeneic dorsal root ganglia in adult rats: evidence for possible central ingrowth? Exp Neurol 115:158-162.

Rossino P, Gavazzi I, Timpl R, Aumailley M, Abbadini M, Giancotti F, Silengo L, Marchisio PC, Tarone G (1990) Nerve growth factor induces increased expression of a laminin-binding integrin in rat pheochromocytoma PC12 cells. Exp Cell Res 189:100-108. 
Rubin BP, Dusart I, Schwab ME (1994) A monoclonal antibody (IN-1) which neutralizes neurite growth inhibitory proteins in the rat CNS recognizes antigens localized in CNS myelin. J Neurocytol 23:209-217.

Savio T, Schwab ME (1989) Rat CNS white matter, but not gray matter, is nonpermissive for neuronal cell adhesion and fiber outgrowth. J Neurosci 9:1126-1133.

Schnell L, Schwab ME (1990) Axonal regeneration in the rat spinal cord produced by an antibody against myelin-associated neurite growth inhibitors. Nature 343:269-272.

Schreyer DJ, Skene JH (1993) Injury-associated induction of GAP-43 expression displays axon branch specificity in rat dorsal root ganglion neurons. J Neurobiol 24:959-970.

Smith-Thomas LC, Stevens J, Fok-Seang J, Faissner A, Rogers JH, Fawcett JW (1995) Increased axon regeneration in astrocytes grown in the presence of proteoglycan synthesis inhibitors. J Cell Sci 108: 1307-1315.

Sterne GD, Brown RA, Green CJ, Terenghi G (1998) NT-3 modulates NPY expression in primary sensory neurons following peripheral nerve injury. J Anat 193:273-281.

Stewart HJ, Cowen T, Curtis R, Wilkin GP, Mirsky R, Jessen KR (1992) GAP-43 immunoreactivity is widespread in the autonomic neurons and sensory neurons of the rat. Neuroscience 47:673-684.

Tang S, Woodhall RW, Shen YJ, DeBellard ME, Saffell JL, Doherty P, Walsh FS, Filbin MT (1997) Soluble myelin-associated glycoprotein (MAG) found in vivo inhibits axonal regeneration. Mol Cell Neurosci 9:333-346.

Thomas PK, Ochoa J, Berthold CH, Carlstedt T, Corneliuson O (1993) Microscopic anatomy of the peripheral nervous system. In: Peripheral neuropathy (Dyck PJ, Thomas PK, eds), pp 28-91. Philadelphia: W.B. Saunders.

Tong YG, Wang HF, Ju G, Grant G, Hokfelt T, Zhang X (1999) Increased uptake and transport of cholera toxin B-subunit in dorsal root ganglion neurons after peripheral axotomy: possible implications for sensory sprouting. J Comp Neurol 404:143-158.

Verge VM, Tetzlaff W, Bisby MA, Richardson PM (1990a) Influence of nerve growth factor on neurofilament gene expression in mature primary sensory neurons. J Neurosci 10:2018-2025.
Verge VM, Tetzlaff W, Richardson PM, Bisby MA (1990b) Correlation between GAP43 and nerve growth factor receptors in rat sensory neurons. J Neurosci 10:926-934.

Verge VM, Merlio JP, Grondin J, Ernfors P, Persson H, Riopelle RJ, Hokfelt T, Richardson PM (1992) Colocalization of NGF binding sites, trk mRNA, and low-affinity NGF receptor mRNA in primary sensory neurons: responses to injury and infusion of NGF. J Neurosci 12:4011-4022.

Verge VM, Richardson PM, Wiesenfeld-Hallin Z, Hokfelt T (1995) Differential influence of nerve growth factor on neuropeptide expression in vivo: a novel role in peptide suppression in adult sensory neurons. J Neurosci 15:2081-2096.

Wujek JR, Lasek RJ (1983) Correlation of axonal regeneration and slow component B in two branches of a single axon. J Neurosci 3:243-251.

Yang H, Xiao ZC, Becker B, Hillenbrand R, Rougon G, Schachner M (1999) Role for myelin-associated glycoprotein as a functional tenascin-R receptor. J Neurosci Res 55:687-701.

Z'Graggen WJ, Metz GA, Kartje GL, Thallmair M, Schwab ME (1998) Functional recovery and enhanced corticofugal plasticity after unilateral pyramidal tract lesion and blockade of myelin-associated neurite growth inhibitors in adult rats. J Neurosci 18:4744-4757.

Zhang Y, Winterbottom JK, Schachner M, Lieberman AR, Anderson PN (1997) Tenascin-C expression and axonal sprouting following injury to the spinal dorsal columns in the adult rat. J Neurosci Res 49:433-450.

Zhang Y, Tohyama K, Anderson PN, Haque N, Martindale J, Schachner M, Lieberman A (1999) R. axonal regeneration, astrocyte morphology and the expression of extracellular matrix molecules following dorsal rhizotomy in adult rats. Soc Neurosci Abstr 295:10.

Zhang Z, Tarone G, Turner DC (1993) Expression of integrin alpha 1 beta 1 is regulated by nerve growth factor and dexamethasone in PC12 cells. Functional consequences for adhesion and neurite outgrowth. J Biol Chem 268:5557-5565.

Zuo J, Ferguson TA, Hernandez YJ, Stetler-Stevenson WG, Muir D (1998) Neuronal matrix metalloproteinase-2 degrades and inactivates a neurite-inhibiting chondroitin sulfate proteoglycan. J Neurosci 18: 5203-5211. 